\title{
Hastanenin tekrar tercih edilebilirliğinin lojistik regresyon ile incelenmesi
}

\section{Analyzing the re-preference of the hospital by logistic regression}

\author{
Serap YORUBULUT*, Funda ERDUGAN
}

Kırıkkale University, Faculty of Arts and Sciences, Department of Statistic, Kırıkkale/Türkiye

\section{öz}

Amaç: Hastanenin tekrar tercih edilmesi kurum açısından memnuniyetin bir göstergesidir. Bu çalışmada hastanenin tekrar tercih edilmesi üzerinde etkili olduğu düşünülen cinsiyet, yaş, eğitim durumu gibi demografik değişkenler ile birlikte memnuniyet faktörleri olarak belirlenmiş olan hekim, fiziki olanak ve çalışan personelin etkisinin lojistik regresyon analizi ile açıklanması amaçlanmıştır.

Gereç ve Yöntemler: Araştırmanın örneklemine Kırıkkale Üniversitesi Tıp Fakültesi Hastanesi polikliniklerine başvuran 1349 hasta dahil edilmiştir. Hastalar tabakalı rasgele örnekleme yöntemi ile belirlenmiştir.

Bulgular: Hastanenin tekrar tercih edilmesinde demografik değişkenlerden cinsiyet, yaş ve eğitim durumu değişkenlerinin istatistiksel olarak önemli $(p<0,05)$ olduğu bulunmuştur. Memnuniyet faktörlerinden ise fiziki olanak ve hekim faktörünün istatistiksel olarak önemli olduğu, çalışan personelin tekrar tercihte önemli olmadığı sonucuna ulaşılmıştır.

Sonuçlar: Bu çalışmanın sonucunda, hastanenin tekrar tercih edilmesinde hastanın cinsiyet, yaş ve eğitim durumu ile birlikte hekimlerden ve hastane fiziki olanaklarından duydukları memnuniyet düzeyinin önemli olduğu belirlenmiştir. Sağlık kurumları tekrar tercihte önemli olan bu değişkenleri göz önüne alarak yeni stratejiler geliştirme çabası içinde olmalıdır.

Anahtar kelimeler: Hastanenin tekrar tercih edilmesi, Hasta memnuniyeti, Sağlık hizmetleri 


\section{ABSTRACT}

Aim: It is a sign of pleasure for the institution to choose the hospital again. In this study, demographic variables such as gender, age, educational status and satisfaction factors as physician, physical facility and employee's factors which are thought to be effective on the re-preference of the hospital are aimed to be explained by the logistic regression analysis

Material and Methods: The sample of the study included 1349 patients who applied to the outpatient clinics of Kırıkkale University Medical Faculty Hospital. Patients were determined by stratified random sampling method.

Results: The demographic variables were found to be statistically significant $(p<0.05)$ for gender, age and educational status for re-preference of the hospital. Physician and physical facility factors were found to be statistically significant but employee's factor was not important in re-preference.

Conclusion: As a result of this study, the re-preference of the hospital was determined with respect to the gender, age and educational status of the patient, as well as the level of satisfaction of the patient for physician and the hospital physical facilities. Health institutions should be in an effort to develop new strategies, taking into consideration the variables that are important to re-preference.

Keywords: Re-preference of the hospital, Patient satisfaction, Health care

\section{Giriş}

İnsanlık tarihi ile eş anlı olarak başlayan sağlık hizmetleri toplum açısından son derece önemlidir. Hızla değişen günümüz koşullarında sağlık hizmetlerini sunan kuruluş olarak hastaneler teşhis, tedavi ve bakım hizmetlerini başarı ile gerçekleştirmenin yanı sıra hasta memnuniyet düzeylerini yüksek tutmayı da amaçları arasına almıştır.

Hasta memnuniyeti, genel olarak "hastaların istek ve beklentilerinin karşılanması veya bu istek ve beklentilerin üstünde hizmet verilmesi" olarak tanımlanabilir [1]. Hasta memnun kaldığında bir daha gereksinim duyması halinde, duyduğu memnuniyet hastanın o hastaneyi tekrar tercih etmesinde etkili olmaktadır [2]. Memnun edilmiş hastaların hastaneye karşı güveni artmakta ve dolayısıyla o hastaneye olan bağlılığı da artmaktadır. Bu bağlamda memnuniyetin, hastane tercihini etkileme noktasında başlıca bir rol oynadığı söylenebilir [3]. Hasta tarafından tekrar tercih edilmek, hastanenin imaj ve itibarını güçlendirir. Her alandaki kurum ve kuruluşlar, rekabet koşullarında daha fazla tercih edilebilir olma ve dolayısıyla gelirlerini artırma amacı ile imaj çalışmalarına büyük zaman, emek ve kaynak ayırmaktadırlar. Güçlü ve olumlu bir imaj, kurumun hedef kitlelerince doğru algılanmasını sağlayabilen etkili bir yöntemdir [4].

Hasta bağlıığı kavramı, genel işletmecilik açısından ele alınan "müşteri bağlıı̆̆ının" hastane hizmetlerine uyarlanmış halidir [5]. Tıpkı müşteri bağlıı̆ı kavramında olduğu gibi, müşteri güveni, müşteri sadakati ve müşteri özdeşleşmesi kavramları hasta güveni, hasta sadakati ve hasta özdeşleşmesi olarak uyarlanmıştır [6].

Türkiye'de yapılan bazı çalışmalarda hasta memnuniyetinin hastaların hastaneyi tekrar tercih etme ve başkalarına tavsiye etme kararları üzerinde etkili olduğu sonucuna varılmıştır. Hasta ile hekim arasındaki bilgi asimetrisinden dolayı, hastalar kendilerine sunulan tıbbi hizmetleri tam olarak değerlendirememektedirler [7].

[5] çalışmasında hasta memnuniyetinin hasta bağlılığı üzerinde önemli derecede etkili olduğu hem korelasyon analizi hem de çoklu regresyon analizi ile incelemiş, hasta bağııı̆ının en fazla ilgi ve nezaket boyutundan etkilendiği sonucuna ulaşılmıştır. Bunu idari hizmetlerden memnuniyet ve son olarak da tıbbi hizmetlerden memnuniyet boyutları takip etmektedir [5, 8-10].

\section{Gereç ve Yöntemler}

Kırıkkale Üniversitesi Tıp Fakültesi hastanesinde çeşitli polikliniklerden sağlık hizmeti alan hastalar bu çalışmanın araştırma kitlesini oluşturmaktadır. Örneklem sayısının belirlenmesinde olasılıksal örnekleme yöntemlerinden tabakalı rasgele örnekleme yöntemi kullanılmıştır. Kırıkkale il nüfusu ve hastaneye başvuran hasta sayısı dikkate alınarak \%95 güven düzeyinde ve 0,01 hoşgörü miktarına göre 1349 hasta araştırma örneklemini oluşturmuştur. Hastalara yüz yüze anket yapılarak veri toplama süreci tamamlanmıştır. Gönüllülük esasına dayalı olarak 18 yaş üstü hastalar rasgele seçilmiştir. Elde edilen veriler oluşturulan veri tabanına aktarılmış, yanlış 
veya eksik veri girişi olup olmadığı kontrol edildikten sonra, istatistiksel değerlendirme aşamasında ise Statistical Package for the Social Sciences (SPSS, version 20.0; SPSS, Chicago, ABD) paket programı kullanılmışır.

\section{İstatistiksel analiz}

Lojistik regresyon analizi, son dönemlerde özellikle sosyal bilimler alanında kullanımı yaygınlaşan bir yöntemdir. Neden sonuç ilişkilerinin ortaya konulması amacıyla yapılan çoğu sosyo-ekonomik araştırmada, incelenen değişkenlerden bazıları olumlu-olumsuz, başarılı-başarısız, evet-hayır, memnunmemnun değil seklinde iki düzeyli verilerden oluşmaktadır. Bu türde bağımlı değişkenin iki düzeyli ya da çok düzeyli kategorik verilerden oluşması durumunda; bağımlı değişken ile bağımsız değişken(ler) arasındaki neden-sonuçilişkisinin incelenmesinde, Lojistik Regresyon Analizi önemli bir yere sahiptir [11].

Bu çalışmada, Kırıkkale Üniversitesi Tıp Fakültesi hastanesinden sağlık hizmeti alan hastaların, tekrar aynı hastaneyi tercih etme durumunun çok değişkenli lojistik regresyon analizi ile açıklanması hedeflenmiştir. Analizde hastaların hastaneyi tekrar tercih etmeyi isteyip istememesi açıklanan değişken olarak ele alınmıştır. Bu değişken nominal ölçekli iki kategorili bir değişkendir. Cinsiyet, yaş, eğitim durumu gibi demografik değişkenler ile beraber hastanenin fiziki olanaklarından, hekimlerinden ve diğer hastane personelinden duyulan memnuniyet faktörleri ise açıklayıcı değişkenler olarak ele alınmıştır. Bu açıklayıcı değişkenlerden ise cinsiyet, fiziki olanak, hekim ve diğer personelden duyulan memnuniyet faktörleri kategorik değişkenler olup, yaş ve eğitim durumu ise ordinal ölçekli değişkenlerdir. İstatistiksel anlamlılık sınırı $\mathrm{p}<0,05$ olarak kabul edilecektir.

Doğrusal regresyon modeli açıklayıcı değişkenin bilinen bir değerine karşılık açıklanan değişkenin ortalama değeri olarak$$
E(Y / X)=\beta_{0}+\beta_{1} X
$$

şeklinde ifade edilebilen koşullu beklenen değerdir. Açıklanan değişkenin aldığı değerlerin 0 ve 1 şeklinde binary olduğu durumda, doğrusal regresyon modeli için gerekli varsayımlara ihtiyaç duyulmadığında lojistik regresyon modeli kullanılır. Lojistik regresyon fonksiyonu

$$
\pi(\underline{x})=\frac{\exp \left(\beta_{0}+\beta_{i} \underline{x}\right)}{1+\exp \left(\beta_{0}+\beta_{i} \underline{x}\right)}
$$

şeklindedir. Lojistik regresyon analizinin temelinde $\pi(\underline{x}) /(1-\pi(\underline{x}))$ şeklinde ifade edilen "odds oranı" kavramı yer alır. Bu oran bir olayın meydana gelme sayısının gelmeme sayısına oranıdır.

$g(\underline{x})=\ln \left(\frac{\pi(\underline{x})}{1-\pi(\underline{x})}\right)=\beta_{0}+\beta_{i} \underline{x}$

(1) eşitliği ile verilen odss oranı doğal logaritması alınarak doğrusal modele dönüşür.

\section{Bulgular}

Araştırmaya katılan hastaların \%62 si kadın, \%70,4 ü evli, \%44 ü 40 yaş üstü, \%32,6 sı ise lise mezunu durumundadır. Ayrıca ikametgah yerine bakıldığında hastaların \%67,5 i Kırıkkale il merkezinden gelmektedir. Hastalara ait tanımlayıc bilgiler Tablo 1'de verilmiştir.

\begin{tabular}{|c|c|c|c|}
\hline Özellik & Düzey & Frekans (f) & Yüzde (\%) \\
\hline \multirow[t]{2}{*}{ Cinsiyet } & Kadın & 836 & 62,0 \\
\hline & Erkek & 513 & 38,0 \\
\hline \multirow{3}{*}{ Medeni Durum } & Evli & 950 & 70,4 \\
\hline & Bekar & 372 & 27,6 \\
\hline & Ayrılmış & 27 & 2,0 \\
\hline \multirow[t]{3}{*}{ Yaş } & 25 yaş altı & 312 & 23,1 \\
\hline & $25-40$ & 444 & 32,9 \\
\hline & 40 yaş üstü & 593 & 44 \\
\hline \multirow[t]{4}{*}{ Eğitim Durumu } & $\begin{array}{l}\text { Okur-yazar ve okur- } \\
\text { yazar olmayan }\end{array}$ & 139 & 10,3 \\
\hline & İlköğretim & 403 & 29,9 \\
\hline & Lise & 440 & 32,6 \\
\hline & Üniversite ve üstü & 367 & 27,2 \\
\hline \multirow[t]{4}{*}{ İkamet yeri } & İl merkezi & 910 & 67,5 \\
\hline & İlçe & 278 & 20,6 \\
\hline & Köy/Kasaba & 94 & 7,0 \\
\hline & Diğer iller & 67 & 5,0 \\
\hline
\end{tabular}

Anket çalışması sonucu elde edilen verilerden hastaların hastaneyi tekrar tercih etme durumunu etkileyen faktörleri belirlemek amacıyla model kurulmuştur. Bu çalışmada cinsiyet, yaş, eğitim durumu, hastanenin fiziki olanak, personel ve hekimlerinden duyulan memnuniyet şeklinde olan açıklayıcı değişkenler yardımıyla tekrar tercih etme durumu açıklanmıştır.

Açıklayıcı değişkenler, cinsiyet değişkeni 1: "kadın", 2: "erkek" şeklinde nominal değişken olarak; yaş değişkeni 1: "25 yaş altı", 2: "25-40 arası", 3: "40 yaş üstü" şeklinde ordinal değişken olarak; hastaların eğitim durumları 1:"okur-yazar ve okur-yazar olmayan", 2: "ilköğretim", 3:"lise", 4: "üniversite ve üstü" şeklinde ordinal değişken olarak kodlanmıştır. [12] çalışmasında hasta 
memnuniyet düzeylerinin belirlenebilmesi için 1: Çok Kötü, 2: Kötü, 3: Orta, 4: İyi ve 5: Mükemmel şeklinde derecelendirilmiş 5'li Likert ölçeği ile "fiziki olanak", "diğer personel" ve "hekim" faktörleri elde edilmiştir. Memnuniyet düzeyini belirlemede etkili olduğu düşünülen bu faktörler iki kategorili değişkene dönüştürülmüştür. Açıklanan değişken ise 0: "tekrar tercih etmeme", 1: "tekrar tercih etme" olarak sınıflandırılmıştır.

Lojistik regresyon analizinde parametrelerin anlamlılığının sınanmasındaWaldveOmnibustestlerisıklıklakullanılmaktadır. Bu amaç doğrultusunda parametrelerin önemi sırasıyla Wald istatistiği ve Omnibus testi ile incelenmiştir.

Lojistik regresyon modelinde yer alabilecek değişkenler için katsayıların ayrı ayrı önemliliği Wald test istatistiği kullanılarak

Ho: $\beta_{i}=0$

Ha: $\beta_{i} \neq 0$

hipotezleri ile sınanmıştır.

Tekrar tercih etme durumu ile ilişkili olduğu düşünülen risk faktörleri, çok değişkenli lojistik regresyon analiziyle belirlenmiştir. Tablo 2 ile verilen değişkenlere ait modeldeki katsayıların tahmin ( $\hat{\beta})$, tahminlerin standart hatası (S.E.), Wald istatistikleri, serbestlik dereceleri (s.d.), katsayıların anlamlılığı (p), tahminlerin odss oranı $(\operatorname{Exp}(\hat{\beta}))$ odds oranı için \%95 güven aralığı değerleri verilmiştir.

\begin{tabular}{|c|c|c|c|c|c|c|c|c|}
\hline & $\hat{b}$ & S.E. & Wald & s.d. & $p$ & $\begin{array}{l}\text { Exp } \\
\hat{b}\end{array}$ & $\begin{array}{l}\text { \%95 gü } \\
\text { aralığı } \\
\text { Alt }\end{array}$ & $\begin{array}{l}\text { üven } \\
\text { Üst }\end{array}$ \\
\hline $\begin{array}{l}\text { Cinsiy- } \\
\text { et(1) }\end{array}$ & ,482 & 143 & 11,374 & 1 & ,001 & 1,620 & 1,224 & 2,144 \\
\hline Yaş & & & 7,595 & 2 & ,022 & & & \\
\hline Yaş (1) & , 157 & , 181 & ,755 & 1 & ,385 & 1,170 & ,821 & 1,668 \\
\hline Yaş (2) &, 543 & ,206 & 6,967 & 1 & ,008 & 1,721 & 1,150 & 2,576 \\
\hline Eğitim & & & 10,437 & 3 & ,015 & & & \\
\hline Eğitim(1) & ,732 & ,243 & 9,095 & 1 & ,003 & 2,079 & 1,292 & 3,345 \\
\hline Eğitim (2) & ,639 & ,246 & 6,771 & 1 & ,009 & 1,895 & 1,171 & 3,067 \\
\hline Eğitim (3) &, 451 & ,260 & 3,013 & 1 & ,083 & 1,570 & ,943 & 2,611 \\
\hline $\begin{array}{l}\text { Personel } \\
\text { (1) }\end{array}$ & 124 & , 184 &, 456 & 1 &, 500 & 1,132 & 790 & 1,623 \\
\hline Hekim (1) & ,516 & , 181 & 8,098 & 1 & ,004 & 1,675 & 1,174 & 2,390 \\
\hline $\begin{array}{l}\text { Fiziki ola- } \\
\text { nak (1) }\end{array}$ &, 373 & 172 & 4,706 & 1 & ,030 & 1,452 & 1,037 & 2,033 \\
\hline Sabit &,- 511 & ,317 & 2,596 & 1 & 107 & ,600 & & \\
\hline
\end{tabular}

Bu tablo incelendiğinde cinsiyet değişkeni hastanenin tekrar tercihinde önemli ( $p=0,001)$ olup, kadınların erkeklere göre 1,62 kat daha fazla hastaneyi tekrar tercih edebileceği görülmüştür. Yaş değişkeni tekrar tercih etmede önemli $(p=0,022)$ olup, 25 yaş altı referans kategorisi olarak alındığında 40 yaş üstü hastaların 1,72 kat hastaneyi daha fazla tercih ettiği sonucuna ulaşılmıştır. Eğitim durumunun modelde önemliliği $(p=0,015)$ belirlenip, okur-yazar ve okur-yazar olmayan hastalar referans kategorisi olarak alındığında ilköğretim mezunlarının 2,08 kat, lise mezunlarının 1,89 kat ve üniversite ve üstü mezunlarının 1,57 kat daha fazla tekrar hastaneyi tercih ettiği saptanmıştır. Hasta memnuniyeti üzerinde etkili olan faktörlerden "personel" oluşturulan lojistik regresyon modelinde istatistiksel olarak anlamsız bulunmuştur. Hastanenin "fiziki olanak" faktörü tekrar tercih edilebilirlikte önemli olup, fiziki olanaklardan memnun olan hastalar 1,45 kat memnun olmayanlara göre daha fazla tercih etmiştir. Hasta memnuniyeti üzerinde etkili olan "hekim” faktörü ise modelde önemli bulunup, hekimlerden memnun olan hastalar memnun olmayanlara göre 1,68 kat daha fazla tekrar geleceğini belirtmişlerdir. Ayrıca sabit terim modelde önemsiz bulunmuştur.

Modelin anlamlılığı için yapılan Omnibus testi ile sınanacak olan hipotez;

Ho: Model anlamsizdir $\left(\beta_{1}=\beta_{2}=\cdots=\beta_{k}=0\right)$ Ha: Model anlamlıdır (En az bir $\beta_{i} \neq 0$ ) olup model anlamlı $\left(\chi^{2}=68,040, \mathrm{p}=0,00\right) \quad$ olarak bulunmuştur.

Modelin uyum iyiliğini değerlendirmek için parametrelerin anlamlılığının sınanmasında kullanılan Wald ve Omnibus testlerine alternatif bir yöntem ise Hosmer ve Lemeshow testidir.

Modelin uyum iyiliğinin ölçüsü olarak Hosmer Lemeshow testi için Ho: Model uygundur

Ha: Model uygun değildir

şeklinde oluşturulan hipotezlerin sınanması sonucunda $\left(\chi^{2}=6,368 \mathrm{p}=0,606\right)$ modelin uygunluğu belirlenmiştir.

\section{Tartışma}

Sağlık sektöründe günümüz koşullarında rekabetin yoğun yaşanması, hastaların gidecekleri hastaneyi tercih etme nedenlerini daha önemli hale getirmektedir. Hastaların bir hastaneyi tercih etme sebepleri arasında hasta memnuniyet düzeyinin önemli bir yere sahip olduğu kaçınılmaz bir gerçektir. Hastaneler de diğer kurumlar gibi kendilerini değişen şart ve taleplere göre ayak uydurmak zorundadır. Hastalar tarafından tekrar tercih edilebilme hastane açısından hedeflenen bir 
durumdur. Tekrar tercih edilebilmek ise birçok faktöre bağlıdır. [3] hastane tercihinde etkili olan faktörleri bulmuş ve önem derecesine göre sıralamıştır. En çok etkili olan ilküç faktörü sırasıyla güven, uzman doktor tercihi ve memnuniyet olarak belirlemiştir. Tercih etmemede ise etkili olan üç özellik sırası ile doktor ilgisizliği, yetersiz muayene ve hoşgörü olmaması şeklindedir.

[13] yaş ve medeni duruma göre özel hastanelerin yaptığı tanıtımın, hastanenin prestijine, tanınırlığına ve tercih edilirliğinde önemli etkisinin olduğunu belirlemiştir.

[14] yaptıkları çalışmada hizmet kalite boyutları ile hastaneyi tekrar tercih etme niyeti arasındaki ilişkiyi korelasyon analizi ile incelemiştir. Bu analiz sonucunda ise fiziksel varlıklar, güvenilirlik, cevap verebilirlik, güven, özdeşleştirme şeklinde isimlendirilen hizmet boyutları ve genel hizmet kalitesi ile hastaneyi tekrar tercih etme niyeti arasında anlamlı ilişkiler bulunmuş olup, algılanan hizmet kalitesi arttıkça hastaların hastaneyi tekrar tercih etme niyetinin de artmakta olduğu sonucuna ulaşılmıştır. Hasta memnuniyetini etkileyen faktörlerin incelenmesi üzerine pekçok çalışma mevcuttur. Ancak hastanenin tekrar tercih edilmesinde etkili olan faktörlerin belirlenmesine ilişkin çalışma sayısı sınırlıdır. Bu çalışmada hastaların tekrar aynı hastaneyi tercih etmelerinde etkili olduğu düşünülen değişkenler lojistik regresyon analizi ile irdelenmiştir. Yapılan çok değişkenli lojistik regresyon analizi sonucunda cinsiyet, yaş, eğitim durumu gibi demografik değişkenler ile beraber fiziki olanaklardan ve hekimlerden duyulan memnuniyetin istatistiksel açıdan önemli olduğu sonucuna ulaşılmıştır.

Kırıkkale Üniversitesi Tıp Fakültesi Hastanesine başvuran hastalar incelendiğinde; cinsiyet önemli olup, kadınların daha çok hastaneyi tekrar tercih ettikleri görülmüştür. Yaş değişkenine göre ise yaş ilerledikçe aynı hastaneyi tercih etme durumunun arttığı, eğitim seviyesi arttığında ise tekrar tercih edilme isteğinin ters orantılı olduğu görülmüştür.

Erdugan, Yörübulut vd. (2017) çalışmasında aynı örneklem grubu için hasta memnuniyetini etkileyen faktörler "Personel", "Fiziki olanak" ve "Hekim" olarak adlandırılıp "iyi" düzeyde bulunmuştur. Bu faktörlerin ise hastanenin tekrar tercih edilebilirliğinde "Fiziki Olanak" ve "Hekim" faktörünün önemli olduğu ancak "Personel" faktörünün önemsiz olduğu saptanmıştır. Buradan yola çıkarak hekimin mesleki yeterliliğinin yanı sıra hastasıyla kurduğu iletişim, hoşgörü, ilgi, alaka, verdiği motivasyon tekrar tercih edilmede önemlidir.

Bir hastane için kullanılan binaların yeni, geniş ve modern imkanlarla donatılması, temizliği, birimler arası ulaşımın kolaylığı, kullanılan teknik araç-gereç ve ekipmanların yeterliliği gibi fiziki olanaklardan duyulan memnuniyet derecesi hastanenin tekrar tercih edilmesinde etkilidir.

Hastaları tarafından tekrar tercih edilen bir hastane olmak, hastanenin kaliteli, prestijlive güvenilir olmasının göstergesidir. Sonuç olarak tekrar tercihte hastaların bazı demografik özelliklerinin önemli olmasının yanı sıra hekim memnuniyeti ve fiziki olanak memnuniyetinin de lojistik regresyon analizi ile istatistiksel olarak da önemliliği görülmüştür. Hastaneler bu sonuçları göz önüne alarak sürekli olarak imkan, donanım, teknik yapı gibi olanaklarını güncel tutmalı ve hekim başta olmak üzere tüm çalışanlarının bilgi, beceri ve tecrübesine ek olarak hastaya vereceği ilgi, alaka ve güçlü bir iletişimi sağlamaya önem vermelidir.

\section{Teşekkür}

Bu çalışma, Kırıkkale Üniversitesi Bilimsel Araştırma Projeleri (BAP) Koordinasyon Birimi tarafından (Proje No: 2015/40) desteklenmiştir. BAP koordinasyon birimine, Kırıkkale Üniversitesi Tıp Fakültesi Hastanesi başhemşire yardımcısı Elçin Şahin'e araştırma verilerinin toplanması aşamasında gösterdiği destekten ötürü, ayrıca bilgisayar ortamına anket verilerinin girişi konusunda destek veren Kırıkkale Üniversitesi İstatistik Bölümü öğrencilerine teşekkürlerimizi sunarız.

\section{Kaynaklar}

1. Soysal A, Öke P, Yağar F, Kılıç B. Hastaların sigortalı olma durumları ve hasta memnuniyeti düzeylerinin incelenmesi: özel hastane örneği. Uluslararası Sosyal Araştırmalar Kongresi (USAK'17) İstanbul. 20-22 Nisan 2017.

2. Özer A, Çakıl E. Sağlık hizmetlerinde hasta memnuniyetini etkileyen faktörler. Tıp Araştırmaları Dergisi 2007; 5.

3. Tüfekçi $N$, Asığbulmuş $H$. Hasta memnuniyeti ve hastane tercihinde etkili olan faktörler: Isparta ili örneği. Journal of Current Researches on Health Sector 2016; 6: 71-92.

4. Güleç ŞN. Özel hastane tercihinde kurumsal imajın rolü. Sosyal Bilimler Dergisi, The Journal of Social Science. 2017; 4: 275-92.

5. Erdem R, Rahman S, Avcı L, Demirel B, Köseoğlu S, Fırat G, Kesici T, Kırmızıgül Ş, Üzel S, Kubat C. Hasta memnuniyetinin hasta bağlıığı üzerine etkisi. Erciyes Üniversitesi İktisadi ve İdari Bilimler Fakültesi Dergisi 2008; 31: 95-110.

6. Derin N, Demirel ET. Hasta görüşlerine göre oluşan kurum ünü ile hasta tutum ve davranışları arasındaki ilişkinin incelenmesi: Turgut Özal Tıp Merkezi örneği. Fırat Üniversitesi Sosyal Bilimler Dergisi 2011; 21: 208-35. 
7. Erdem R, Yıldııım HH. Sağlık hizmetlerinde vekalet ilişkisi ve arzın talep yaratması problemi. Hacettepe Sağlık İdaresi Dergisi 2003; 6: 3-26.

8. Dursun $Y$, Çerçi M. Algılanan sağlık hizmeti kalitesi, algılanan değer, hasta tatmini ve davranışsal niyet ilişkileri üzerine bir araştırma. Erciyes Üniversitesi İktisadi ve İdari Bilimler Fakültesi Dergisi 2004; 23: 1-16.

9. Varinli i, Çakır A. Hizmet kalitesi, değer, hasta Tatmini ve davranışsal niyetler arasındaki ilişki -Kayseri'de poliklinik hastalarına yönelik bir araştırma. Erciyes Üniversitesi Sosyal Bilimler Enstitüsü Dergisi 2004; 17: 33-52

10. Ibanez VA, Hartmann P, Calvo PZ. Antecedents of costumer loyalty in residentila energy markets: service quality, satisfaction, trust and switching costs", The Service Industries Journal 2006; 26: 633-50.

11. Girginer N, Cankuş B. Tramvay yolcu memnuniyetinin lojistik regresyon analiziyle ölçülmesi: estram örneği. Yönetim ve Ekonomi: Celal Bayar Üniversitesi İktisadi ve İdari Bilimler Fakültesi Dergisi 2008; 15: 181-93.
12. Erdugan F, Yörübulut S, Şahin E, Öncel SY. Kırıkkale Üniversitesi Tıp Fakültesi Hastanesinde hasta ve çalışan memnuniyeti. Mehmet Akif Ersoy Üniversitesi Sosyal Bilimler Enstitüsü Dergisi 2017; 9: 165-77.

13. Belber BG. Yaş ve medeni duruma göre "özel hastanelerin yaptığı tanıtımın" hastanenin prestijine, tanınırlığına ve tercih edilirliğine etkisi: Nevşehir uygulaması. International Journal of Social Sciences and Education Research 2015; 1: 424-38.

14. Korkmaz S, Çuhadar U. Sağlık hizmet kalitesi ve sağlık kurumunu tekrar tercih etme niyeti arasındaki ilişki: eğitim ve araştırma hastanesi örneği. Uluslararası sağlık yönetimi ve stratejileri araştırma dergisi 2017; 3: 72-87. 